\title{
ON THE GRAMMAR OF A SENEGALESE DRUM LANGUAGE
}

\author{
YOAD WINTER \\ Utrecht University
}

\begin{abstract}
Senegalese drummers often recite improvised texts while playing, considering the texts to reflect the rhythms' meanings. Unlike in other African traditions, drums are rarely used as a speech surrogate. It is shown here that Senegalese rhythms involve language-like grammar rules, which are partly independent of the grammar of the players' spoken language. The rhythms do not acoustically mimic speech, and the speech-drum matching is based on a lexicon of rhythms and their meanings. Players use this lexicon to produce an unlimited number of meaningful rhythms. The analysis of complex rhythms shows nonlinear alignments with spoken sentences containing plurals, definites, and negation. It is concluded that rhythms are generated by drum-specific grammatical rules. The musical functions of the drum grammar make it especially relevant to current work on language and music, and to ongoing debates between functionalist and formalist approaches to grammar.*
\end{abstract}

Keywords: drum language, music, griots, sabar, Senegal, Wolof, functionalism

1. Introduction. African drumming traditions involving various effects of language-music contact have received much attention since the early 1900s. Ethnographers and musicologists have concentrated on usages of drums as a speech surrogate. These practices of speech surrogacy are often referred to as DRUM LANGUAGES. Despite this common label there has been very little research on the formal linguistic properties of African drumming traditions. Additionally, in the growing body of research on the relations between language and music, there have only been some cursory notes on the significance of drum languages for analyzing these two combinatorial faculties of human cognition.

This article analyzes the formal properties of language-music contact among Senegalese poets, storytellers, and musicians known collectively as GRIOTs (Wolof: géwël). I concentrate on the linguistic-musical traditions of griots who play the single-headed drum known as SABAR, which is very common in both Senegal and Gambia. Traditions of sabar playing involve reciting texts in contiguity with the drum sounds, the texts being considered to be the meanings of the corresponding rhythms. Despite some correlations with speech prosody, the rhythms do not acoustically mimic the spoken utterances. How-

\footnotetext{
* This research would not have been possible without the hard work and patience of all the griot consultants. I am indebted to the sabar grandmaster Doudou N'Diaye Rose and his family for their great help and hospitality, and for all the precious knowledge they generously shared with me. Special thanks go to my friends, teachers, and colleagues, the griots Ousmane Mbengue and Mor Coumba N'Diaye Rose. Special thanks for many remarks and much encouragement to: Martin Everaert, Adam Kendon, Gideon Keren, Marijana Marelj, Eric Reuland, Eddy Ruys, Remko Scha, and Joost Zwarts. Thanks to Iye Echa, Ineke van der Ham, Hannah Kalverda, Hannah de Mulder, Arda Nederveen, Marten Postma, Yael Seggev, and Siarhei Uzunbajakau for help with fieldwork, documentation, and data. Thanks also to Nancy Brenner-Golomb, Noam Chomsky, Edit Doron, Patrick Eisenlohr, Danny Fox, Martha Frederiks, Naama Friedmann, Doram Gaunt, Dieynaba Gaye, Alexander Gelfand, Gianluca Giorgolo, Giora Goodman, Galia Hatav, Omar Ka, Ed Keenan, Shifra Kisch, Arnout Koornneef, Fiona McLaughlin, Jacques Mehler, Russell Schuh, Femke Smits, Benjamin Soares, Anna Szabolcsi, Warmolt Tonckens, Jos van Berkum, Theo Veenker, Nina Wiedenhoff, and Rivka Winter. Financial support was provided by the Utrecht Institute of Linguistics OTS and the focus area Neuroscience \& Cognition of the Utrecht University. The author was also supported by an NWO VICI grant 277-80-002. I am grateful to Greg Carlson and three anonymous Language referees for their thorough comments. Remaining errors and misconceptions are exclusively mine.

This article is dedicated to the memory of Yehojachin Brenner, whose keen observations on drum languages in Ghana aroused my interest in the subject. Yehi Zichro Baruch.
} 
ever, griots report solid intuitions about the matching between spoken expressions and sabar rhythms. On the basis of these intuitions, it is possible to construct a lexicon of rhythmic forms and their meanings. This lexicon is substantially smaller than the lexicon of the spoken language, but it inherits some of its properties and allows griots to produce an unlimited number of meaningful rhythms. Because of this generative ability, the correspondence between sabar rhythms and spoken language is studied from a grammatical point of view. It is observed that linear-order relations between parts of complex rhythms often correspond to adjacency relations in their spoken parallels. When such concatenative alignments appear, rhythms and spoken expressions can be described by the same morphosyntactic principles. However, complex rhythms may also exhibit nonconcatenative alignments with spoken expressions. The conclusion is that rhythm production also involves grammatical operations different from those of the spoken language, and that meaningful sabar rhythms deserve to be studied as a separate object for linguistic research, a drum language referred to as SABAR.

Despite its structural similarity to spoken language, Sabar's main communicative function is to affect the hearers rather than to efficiently convey propositions. Hearers are not expected to interpret the meanings of Sabar rhythms, which are often orally recited by the performers. This observation, together with the language-like structural features of Sabar, lends support to a familiar formalist thesis: some central structural properties of musical and linguistic expressions are determined by constraints on the combinatorial faculties of the human mind, and cannot be exclusively inferred from their communicative functions.

I first overview basic functions of Sabar in relation to language-music contact in other drum languages ( $\$ 2$ ). Sociolinguistic background on the main groups of consultants that were studied and details about the fieldwork are given in $\S 3$, and information about Sabar phonemes and lexical items in $\S 4$. The main findings of this work on Sabar morphosyntactic processes are then introduced and their implications discussed ( 55$)$, with concluding remarks on the relevance of Sabar for the functionalism/formalism debate and the relations between music and language (\$6). The appendix mentions some practical aspects of this research.

2. Aspects of Sabar USE. At least since the end of the nineteenth century, the association between language and music in African traditions has received increasing attention from anthropologists and musicologists (Sebeok \& Umiker-Sebeok 1976). Works in anthropology and musicology have primarily focused on cultures in which drums are used as a speech surrogate. As an example, consider drumming traditions among the Akan people of Ghana as documented in Nketia 1963, 1971 (see also Gelfand 2000). Akan is a tonal language, and Nketia describes how drums are used in their so-called SPEECH MODE for mimicking Akan speech sounds.

The drums which are used in [the speech] mode of drumming are those which can make clear and distinctive tone contrasts ... The ATUMPAN is recognized as the principal 'talking' drum of the Akan people. Nearly all the rhythms and tone sequences produced on these drums closely correspond to the rhythms and tones of language texts. ... The speech mode of drumming has in common with other modes of drumming a musical basis. Many drummers learn to play this mode of drumming as sets of rhythms and only latterly as texts. The arrangement of sequences of tone and rhythm, the use of extra beats, extra rhythms not meant to be translated into words, features of repetition, speed, and other stylistic aspects have all to be considered and properly handled in order to enhance musical interest. Nevertheless in a speech mode of drumming, verbal communication is the ultimate goal. Drummers and those who listen in ignorance to the rhythms never lose sight of the fact that the rhythms have the implication of utterances. The musical aspects, though important for recognizing the mode of drumming, are subservient to the texts which they recall. (Nketia 1963:29) 
Like Nketia's work, virtually all previous research on African 'drum languages' has studied drumming among speakers of tonal languages, where drums in different pitches mimic tonal and other phonemic parameters of speech. ${ }^{1}$ The present article studies Senegalese traditions where drums are rarely used as a speech surrogate. Nevertheless, as we see below, these drumming practices systematically show structural linguistic effects even in the absence of speech surrogacy.

Griots are a class of professional poets, oral historians, genealogists, storytellers, and praise-singers in Senegal and other parts of West Africa (Hale 1998). Griots may also be accomplished musicians: singers, percussionists, or players of string instruments. In Senegal and Gambia many of the griots play a single-headed drum called sabar. See Tang 2007 for a detailed musicological and ethnographic description of sabar traditions. The present article concentrates on sabar traditions among griots from the Wolof and the Serer peoples. All of the consultants for this work are Wolof speakers. The Wolof consultants are unilingual Wolof speakers who switch freely between urban Dakar Wolof and their native dialect or variety (when different from urban Dakar Wolof). The Serer consultants are bilingual speakers of Serer-Sine and Wolof, but most of the linguistic data they contributed were in Wolof. ${ }^{2}$

In addition to being skilled musicians, many sabar griots are also masters of the spoken word. On many occasions the role of sabar drums appears to be mainly musical (Tang 2007:Ch. 5). ${ }^{3}$ However, when performing, Wolof and Serer griots may also exhibit poetic virtuosity and recite oral texts corresponding to the rhythms they play. In personal interviews griots often say that 'the sabar can speak', and they utter spoken expressions in correlation to sabar rhythms they play. The grammatical aspects of these language-music interactions are the focus of the present article.

Before embarking on this topic it may be helpful to mention a general remark made by the poet Léopold Senghor (1906-2001, first president of Senegal):

Negro-African civilization stems from a UNITARY vision of the world. ... Because it is an INTEGRAL TECHNIQUE, art is not divided against itself. More precisely, the arts in Black Africa are united to each other, poetry to music, music to dance, dance to sculpture, and sculpture to painting. (Senghor 1964:234, from Arom 1991:7)

The traditional art of Senegalese griots should be appreciated with this remark in mind. At the same time, we should avoid two possible misunderstandings. First, sabar griots often play in modern commercial contexts like pop concerts or wrestling contests. In these cases, they function as modern musicians, and, as Tang claims, the relation between Sabar and spoken language remains implicit, if it is present at all. Second, griots may also say that the sabar 'speaks' when they play idiomatic rhythms: for instance, playing their family's rhythm can act as a hortative for summoning people, or playing

\footnotetext{
${ }^{1}$ On drum languages among speakers of Kele (Congo), Banda-Bambari (Central African Republic), and Yorùbá (Nigeria), see Carrington 1949, Cloarec-Heiss 1999, and Villepastour 2010. For more work see Sebeok \& Umiker-Sebeok 1976. Annotated audiovisual material is hard to obtain, but Villepastour's book comes with a CD illustrating the use of bàtá drums in Yorùbá speech surrogacy.

2 On Wolof see Diagne 1971, Munro \& Gaye 1991, Ka 1994, and, on Wolof among griots, Irvine 2011. On Serer-Sine see McLaughlin 1992. For some online material (May 2014) see: http://aflang.humnet .ucla.edu, http://africa.isp.msu.edu/afrlang, http://library.columbia.edu/subject-guides/africa/subjects/wolof _bibliography.html.

${ }^{3}$ Tang's book focuses on the Mbaye family, a family of Wolof griots in Dakar, originally from the town of Kaolack. Based on her observations and interviews (2007:113-14), Tang concludes that most of the Mbaye family's contemporary rhythms are purely musical, and only older rhythms originate in spoken language. As mentioned in $\S 3$, the changes in musical practices that Tang describes also occur in other griot families. However, the findings here show that the tradition of correlating sabar rhythms with spoken language is very much alive, both in Dakar and in other parts of Senegal.
} 
traditional rhythms for a favorite dish can act as a hortative for encouraging the cooks to bring in the food. In the old days griots would sometimes act as town criers, for example, playing a rhythm announcing that a child was lost and shouting accordingly. In such conventionalized circumstances an idiomatic rhythm is used as a simple speech surrogate, but this practice is of little linguistic interest.

The focus of this article is on another traditional setting that better illustrates Senghor's description and is still very common in modern Senegal. In ceremonies like circumcision or marriage, or in other gatherings, griots may demonstrate their skills by inventing new poetry, in tandem with playing corresponding rhythms on the sabar. As an example of this practice consider the following extract from a spontaneous sabar performance. The players are two Wolof-speaking griots (thirty-one and forty-nine) of the LEBU people in Dakar, traditionally a fishing people (Gamble 1957). Addressing the author and his colleague, the two griots improvised the following recitation while playing the sabar. The Wolof text in 1 below is accompanied by sabar rhythms that are not analyzed here. (See example 1 in the online supplementary materials, available at http://muse.jhu.edu /journals/language/v090/90.3.winter01.html, for the audio of this recitation.)

(1) [drumming, then while drumming point at author]

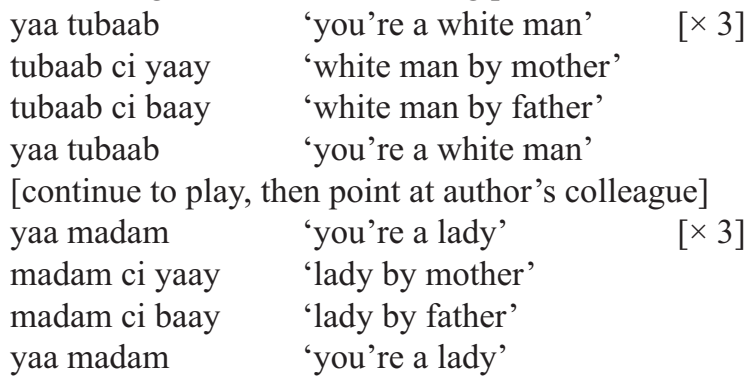

[continue to play, then one griot points at the other, the other points at himself]

$\begin{array}{lll}\text { alaw/alap lebu } & \text { 'you are/I am Lebu' } & \text { [×3] } \\ \text { lebu ca yaay } & \text { 'Lebu by mother' } & \\ \text { lebu ci baay } & \text { 'Lebu by father' } \\ \text { alaw/alap lebu } & \text { 'you are/I am Lebu' }\end{array}$

Sabar playing and improvised poetry, as in 1, are complementary parts of one integral performance. The griots create new texts and rhythms simultaneously on the spot. While the current work does not attempt to give any descriptive characterization of sabar use in 'authentic' performances like 1, it focuses on the linguistic competence of griots in aligning rhythms with speech. It is assumed that this competence is related to the kind of sabar performance illustrated in 1. As we see later, in more controlled linguistic interviews, systematic responses of griots often allow us to characterize structural relations between sabar music and speech.

As noted above, the use of sabar drums as a speech surrogate is negligible. In examples like 1, the main communicative function of the rhythms is musical: they function to affect the hearers rather than to convey complex propositions and concepts. ${ }^{4}$ In a way that may be compared to Western operas or rap performances, the music in 1 has a dra-

\footnotetext{
${ }^{4}$ While music may evoke simple semantic concepts in hearers (Koelsch et al. 2004), the level of accuracy in communicating complex propositions and concepts in language is unparalleled by other natural kinds of communication (Pinker \& Jackendoff 2005). While this is uncontroversial, a hotly debated question is whether the accuracy of linguistic communication may help to explain the evolution of language and its complex syntactic structures. The discussion here is neutral on this question. For further remarks see $\S 6$.
} 
matic function rather than a propositional function: it enhances and strengthens the impact of the words on the listener, but it is not intended to convey literal meanings with any accuracy. Most of the circumstances in which sabar is used have this property. Of course, as an art and an affective mode of expression, sabar practices are a rich topic in their own right. However, the sociological and artistic aspects of the genre, which are effectively studied in Tang 2007, are not addressed here in much detail. The main aim of the present work is to study the structural relations between spoken language and the corresponding sabar rhythms. As is shown, the linguistic structures that sabar rhythms exhibit go far beyond what may be expected from their primarily musical functions and poor usefulness as a speech surrogate.

3. Fieldwork AND methodology. The research reported here is based on interviews carried out between 2008 and 2013 in Senegal and the Netherlands. Four main griot families were interviewed: three Wolof families and one Serer family. ${ }^{5}$ As noted above, the griot consultants were all native speakers of Wolof and/or Serer-Sine who live in Dakar and its environs. However, each of the four families originates from a different location in Senegal and has a different family heritage. Accordingly, each of the groups has a different Sabar repertoire, and even rhythms that have similar meanings are often different. The ad hoc names in Table 1 are used to refer to the four groups and, ambiguously, to their Sabar repertoires.

\begin{tabular}{lll} 
NAME & \multicolumn{1}{c}{ ORIGIN } & \multicolumn{1}{c}{ MAIN LANGUAGES } \\
DW & urban Dakar & urban Dakar Wolof (McLaughlin 2001) \\
RW & rural area north of Dakar & native Wolof dialect, urban Dakar Wolof \\
LW & Lebu (Gamble 1957): traditional & Lebu Wolof, urban Dakar Wolof \\
& fishing people from the Dakar area & \\
SW & emigrant family from Sine Saloum & Serer-Sine, urban Dakar Wolof \\
& \multicolumn{2}{c}{ TABLE 1. Main groups of griots studied. }
\end{tabular}

All of the interviewees were male, and most of them ranged in age from seventeen to sixty. ${ }^{6}$ The interviews were conducted in the lingua franca: urban Dakar Wolof. Other than the DW family, the native languages or dialects/varieties of all of the families are different from urban Dakar Wolof. The native language of the Lebu (LW) family is a variety of Lebu Wolof, which is quite different from urban Dakar Wolof (Gamble 1957). Members of the Serer (SW) family were all bilingual speakers, to various degrees, of Serer-Sine and urban Dakar Wolof. Most of them emigrated to Dakar at an early age and use Wolof interchangeably with Serer-Sine. The rhythms played by this group were referred to in Wolof, except for a few cases (see $\$ 4.3$ ).

In addition to the diversity of family repertoires among Wolof and Serer griots, there are two other diversifying factors affecting the study of Sabar. One of them is the

${ }^{5}$ In pilot studies four additional groups of griots were consulted: three Wolof families from Thiès and Dakar, and another group of griots from M'bour who are native speakers of Susu (a.k.a. Sose; see below).

${ }^{6}$ Although there are female sabar percussionists in Senegal (Tang 2007:24, 78, 89), I have only met two professional female sabar players. Senegalese women from griot families (French: griottes, cf. Hale 1998) are more often dancers, singers, or poets in the Tassou tradition (n. 7). Two interviewees older than seventy were consulted, and one interviewee was sixteen when he was first interviewed. Most children in active griot families are exposed to sabar traditions from childbirth. At the age of three some children can already play basic rhythms on small drums or plastic cans and the like. Children who are as young as five-to-seven years old may sometimes join their family ensemble in private gatherings. The critical question of Sabar acquisition is left for further research. 
changing musical education of griots. Traditionally, griots got most of their sabar training in a group led by a senior family member. Today, with the emergence of commercial art in concerts and TV shows, many griots, especially in Dakar, also play in ensembles outside the family circle. This leads to major differences in sabar practices even within the same griot family. The other diversifying factor is Sabar homophony and synonymy. One rhythm may correspond to different spoken expressions (homophony/ambiguity). Conversely, different griots - and even the same griot on different occasions-may play different rhythmic variations corresponding to the same spoken utterance (synonymy). Similar issues with homophony and synonymy are documented by Nketia regarding the drum language of the Akan, who do (or did) use drums extensively as a speech surrogate (Nketia 1963:841, 860-61). Carrington (1949) and Arom (2007) also make similar remarks on homophony and synonymy with regard to other African communities of speakers of tonal languages using drums as speech surrogates.

To minimize confounds arising because of these factors, most of the data reported below are based on interviews with the senior leader and the older griots in his family. Experience has shown that the sabar practices of older junior griots are often closest to those of their senior peers. Further, two different methods were used in the interviews of griots. Helped by a native Wolof translator, the interviewer asked the griot participant to perform one of the following tasks.

- FREE-RESPONSE TASK: A Wolof expression is uttered by the native assistant, and the participant is asked to play a rhythm corresponding to this expression and to utter the rhythm's oral code (see below).

- Acceptability-Judgment task: The spoken expression is uttered together with a suggested code for the corresponding rhythm. The participant is asked to play the rhythm and judge whether it corresponds to the spoken expression.

The free-response task allowed us to characterize spontaneous correlations between Sabar and spoken utterances, and to compare the responses of different griots. The acceptability-judgment task allowed us to directly test hypotheses about grammatical procedures with Sabar rhythms, and to check possible Sabar synonyms.

Another methodological issue concerns the very small lexicon of the Sabar varieties that were studied (\$4.3). In cases where griots were not able to play a Sabar correlate to a spoken sentence, they often reported that. For instance, after having played his Sabar rendition of the sentence 'I go wash my child', an LW griot was asked to play the parallel of 'I go wash my car'. Laughing, he did not respond and explained that he did not know the rhythm for 'car'. By contrast, some griots consciously invented new rhythms on the spot when they were not sure about well-accepted rhythms. Griots were dissuaded from this practice by being told that 'improvisations' were not requested. In cases where griots explained that they improvised a response because they did not know a common Sabar translation, the response was ignored. See the appendix for more remarks on the research methodology and practical matters regarding the interviews.

\section{Phonemic and lexical units of Sabar.}

4.1. Preliminaries. The formal correspondence of sabar rhythms with spoken language is different from in other African drum languages. As we see in this section, there are no direct acoustic parallels between sabar rhythms and speech. Unlike the documented language-music contact among the Akan and other African communities, Wolof and Serer-Sine are not tonal languages and sabar rhythms do not represent syllable structure or mimic the pitch of speech sounds. The acoustic parallels between sabar 
rhythms and speech, when they exist, are mostly rhythmic/prosodic, and resemble modern rap more than any known African practice of speech surrogacy. ${ }^{7}$ It is the lexical and morphosyntactic correspondences between sabar music and spoken language that best characterize the connections between them. In this sense the language-music contact exhibited by sabar traditions goes far beyond all that is known about rap and other genres of contemporary music.

As noted above, sabar griots systematically associate many of their rhythms with spoken utterances, and the class of such rhythms is referred to here as Sabar. Since Sabar rhythms and their spoken correlates may differ between different communities, we should view the term 'Sabar' as referring to a collection of varieties, rather than to a single drum language. At the same time, the sabar-playing techniques and the practices of associating rhythms with speech are strikingly similar in the different groups of sabar griots that were studied, even when they speak different languages like Wolof, Serer-Sine, or Susu (see below). Within the class of Sabar rhythms, I adopt the standard morphosyntactic distinction between simple and complex expressions. A Sabar rhythm is called COMPLEX if it can be decomposed into simpler Sabar rhythms, that is, two or more rhythms that also have spoken parallels. A Sabar rhythm that cannot be decomposed into simpler Sabar parts is referred to as a SIMPLE rhythm. Many complex rhythms are formed from simpler rhythms by mere concatenation. Consider, for instance, the following two sentences in Lebu Wolof. ${ }^{8}$ (See example 2 in the online supplementary materials for audio of the corresponding sabar rhythms, and example 4 below for the further discussion and description of these rhythms.)

(2) sama doom, lagal ci biir kër gu lëndëm gi (gu leer gi) my child go inside house REL dark the (REL pale the)

'My child, enter the dark (pale) house.'

Each of the two sentences in 2 has a Sabar correlate. Within these correlates, LW griots readily identify two adjacent Sabar rhythms. The first rhythm corresponds to the following Lebu Wolof sentence.

(3) sama doom, lagal ci biir kër gi

my child go inside house the

'My child, enter the house.'

The second rhythm corresponds to the word lëndëm 'dark' or leer 'pale', respectively. Thus, the Sabar rhythm for sentence 2 is classified as complex. By contrast, the rhythms played for lëndëm/leer do not consist of any shorter rhythms with related meanings. Therefore, these rhythms are classified as simple Sabar rhythms. ${ }^{9}$

The rest of this section introduces the phonemic units of sabar rhythms, which include Sabar as well as purely musical rhythms. This repeats, with only minor variations, some details about sabar-playing technique that are documented in Tang 2007. Then we move on to some aspects of the lexical items of Sabar - the minimal sabar rhythms that have concrete translations to spoken language. Sabar morphosyntax is discussed in $§ 5$.

\footnotetext{
${ }^{7}$ Indeed, many Senegalese griots consider their art to be a predecessor of hip-hop music. Especially noteworthy in this respect is TASsou, a form of verbal art traditionally performed by women, which is often accompanied by sabar music (McNee 2000, Tang 2012).

${ }^{8}$ Here and henceforth, the Wolof orthography used is as in Munro \& Gaye 1991 and UCLA's Wolof video course, online at: http://aflang.humnet.ucla.edu/Wolof_video_course.

${ }^{9}$ Whether the Sabar rhythm for 3 is complex is a separate question. The data (seen more clearly in 4 below) do not rule out the possibility that it is an idiomatic rhythm, hence simple. To show that this rhythm is complex we would need to show parts of it that have spoken correlates. To do so would require further study of this example, which is not our purpose here.
} 
4.2. Phonemic Units. The same playing technique is used both for linguistically meaningful Sabar rhythms and in purely musical contexts. As documented in Tang 2007:Ch. 5, sabar sounds are produced by one hand and one stick, both of which are used for beating rhythms and for damping the sound. The basic units of all sabar rhythms are produced by different combinations of applying the hand and the stick on different parts of the sabar head. Griots perceive of some specific drum strokes as minimal units from which longer sabar rhythms are composed. Accordingly, such sabar strokes are referred to as PHONEMES. Each sabar phoneme has an oral code, which griots use when discussing or illustrating rhythms. The phonemes of sabar music can be divided into the following three classes.

- HAND STROKEs: produced by one hand, which may bounce or stop on the skin.

- Stick strokes: produced by the stick, where the hand may be used for damping the sound.

- HAND + STICK STROKEs: sequences of hand strokes and stick strokes; these sequences have their own codes and are perceived as minimal rhythmic units.

The main sabar phonemes, as described by DW consultants, are given in Table 2. (See example 3 in the online supplementary materials for video of the phonemes.) There are three different hand strokes and three different stick strokes. The three hand strokes are commonly referred to as gin, pin, and pax, and the stick strokes are commonly referred to as tan, $t a c$, and $c e$. Most of these names have variants, but the repertoire of six drum strokes is very stable across communities and circumstances of use. The sounds that these six basic strokes produce are the sabar phones. Accordingly, the corresponding phonemes are referred to as 'basic'. The basic phoneme referred to as pax is produced by a hand stroke that has many stylistic variations. Some of these variations have codes of their own like ngax and mbax. The hand + stick strokes are combinations of simple strokes, but they are clearly perceived as distinct phonemes in their own right. For instance, the hand + stick stroke referred to as rwan is often produced as the sequence pin tan or the sequence pax tan. However, the name rwan reflects a perceptual unit that is distinguished from combinations of basic phonemes.

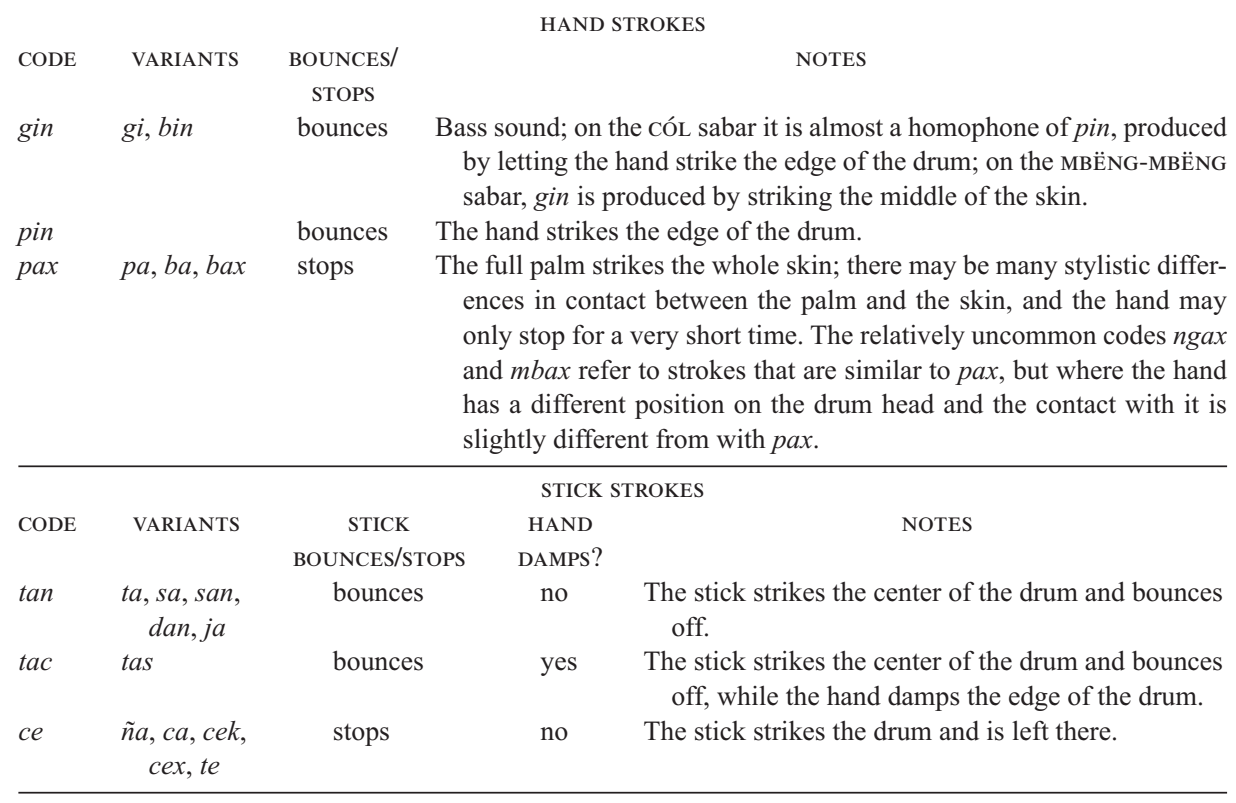




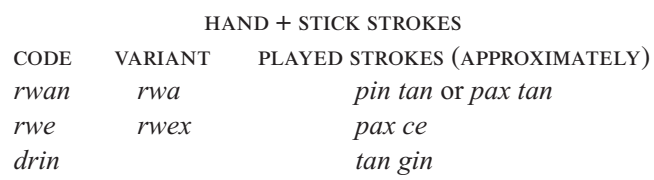

TABle 2. Phonemic units of sabar.

Some of the phonemes may be produced differently on sabars of different types. The code for any given phoneme refers to the way the sound is perceived, not to the precise technique of its production on every specific drum type (Tang 2007:35-38). For instance, the basic phonemes gin and pin are almost homophonic when produced on the sabar type known as cóL (Tang, ibid.). However, griots still distinguish between these phonemes when playing the cól sabar. A phoneme may often have more than one code. The different codes reflect personal choice or dialectal differences, or depend in various ways on the adjacent codes or the speed of playing. For instance, the same phoneme that is referred to orally as gin may be referred to as $g i$ when it appears in a rapid sequence of similar strokes. Specifying the rules that underlie the choice of oral codes for phonemes in a phoneme sequence is an interesting problem that is set aside here.

Among the griot groups that were studied, only slight variations in the inventory of sabar phonemes were found, even between griot communities speaking different languages. Considerable variation was observed in the names used for describing phonemes, but almost no variation in the drum strokes that they refer to. Additionally, Senegalese griots who are native speakers of Susu (a.k.a. 'Sose') were observed to use techniques similar to those of the Wolof and Serer griots interviewed in this research. It should be noted that Susu is standardly classified as belonging to the Mande languages, as opposed to Wolof and Serer-Sine, which are Atlantic languages.

Throughout this article sabar rhythms are represented by their oral codes. For instance, the Sabar rhythm corresponding to the Lebu Wolof sentences in 2 is described by a string of codes as in 4 below. ${ }^{10}$ (See also example 2 in the online supplementary materials.)

(4) Lebu Wolof

$\begin{array}{lll}\begin{array}{l}\text { sama doom, lagal ci biir kër } \\ \text { my child go inside house }\end{array} & \text { gu lëndëm gi } & \text { (gu leer gi) } \\ \text { SABAR } & & \text { (REL pale the) } \\ \text { bax ce gin bax ce gin ce bax ce bax } & \text { tan tan gin } & \text { (tan rwan rwan gin } \\ \quad \text { gin } & & \text { gin) }\end{array}$

The string representation of the Sabar rhythm in 4 does not fully encode duration of notes and breaks within the rhythm. In some cases such notation is crucial for distinguishing between rhythms (cf. gaawal/ñëwal in $\S 4.3$, ma/i doom in $§ 5.2$ ). For most of our purposes, however, the notation in 4 is sufficient. For a more adequate transcription of sabar rhythms see Tang 2007:Ch. 5. It should be noted that there is no attempt here to fully align all spoken expressions with Sabar codes, even in cases like the first part of 4, which is possibly a complex Sabar rhythm. Full alignment would require additional research and would not necessarily contribute to studying the main questions of this article.

As an example of the difficulties in alignment, consider the bass stroke gin, which is often used for stylistic or musical reasons at the beginning or the end of a rhythm. Be-

\footnotetext{
${ }^{10}$ The Sabar correlate of lëndëm is here as given in Table 3 below; the correlate of leer appears here with additional gin strokes, which may be stylistic variation, or may be related to the definite and/or relative items in 2 .
} 
cause of this usage, without further experimentation it may be hard to know which occurrences of gin correlate with grammatical units in the spoken expression, and which occurrences are purely stylistic and may be deleted depending on the griot and the musical context. For instance, the last two gins of the 'pale' rhythm in 4 may be either stylistic or grammatical. This is one of the factors that make full alignment of Sabar and speech a nontrivial matter.

4.3. Lexical items. Many familiar Sabar rhythms cannot be decomposed into linguistically meaningful parts. Accordingly, such rhythms are classified as SIMPLE. The following three classes of simple rhythms can be distinguished.

(5) A. Rhythms, often quite long, corresponding to traditional texts like proverbs and verses (see examples in Tang 2007:Ch. 5).

B. Rhythms corresponding to short spoken expressions, especially exclamatory, imperative, or hortatory sentences like man tamit! 'me too!' (DW), kaay wan më 'come show me' (SW, DW), and nanu dem 'let's go' (DW).

C. Rhythms corresponding to spoken words, especially common nouns, pronouns, proper names, and verbs.

The lines between these three categories are not always easy to draw. For instance, many rhythms corresponding to family names have long versions corresponding to praise poems for these families. Both the short version and its longer renditions may be used as hortatory introductions for imperative sentences (e.g. 'Diouf, let's go!'), but they were not observed to appear as thematic arguments of verbs. Thus, it is unclear if such rhythms for names should be considered as having a grammatical function in Sabar. Also, some simple sentences like kaay wan më 'come show me' have long poetic versions like 'come show it to me, don't hide it from me, come show me', and griots may volunteer idiomatic long versions when asked about the shorter ones. Due to such factors it takes some experimentation to characterize minimal elements of Sabar grammar. For example, in the case of the sentence kaay wan më, SW griots were not able to play rhythms corresponding to paradigmatic variations like kaay wan nu 'come show us'. For this reason the Sabar rhythm for kaay wan më is classified as simple. With other spoken sentences, however, the same griots were able to play rhythms for different personal pronouns (see below). Thus, determining whether a Sabar rhythm is simple or complex involves more than considering the form of its spoken correlate.

The focus here is on the formation of complex Sabar rhythms from simple Sabar rhythms. This formation is most common with those simple rhythms corresponding to spoken words (class $\mathrm{C}$ above) and idiomatic short sentences (class B). These two classes are referred to as the LEXICAL ITEMS of Sabar, or LEXEMES. Rhythms of class A, which correspond to long traditional texts, often do not allow productive combinations into complex Sabar rhythms. Thus, despite their official classification as simple Sabar rhythms, such rhythms are not studied here, and are not classified as Sabar lexemes but as part of the larger class of the musical-poetic idioms of sabar griots. See Tang 2007 for musicological analyses of some of these rhythms.

Some Sabar lexemes are given in Table 3. It should be stressed that this table is selected from a larger collection of responses, and alternate rhythms often exist for the rhythms it contains. Consequently, and independently of morphosyntactic processes, the Sabar lexemes in this table may differ from the relevant parts of Sabar rhythms corresponding to complex expressions containing the lexeme. With the exception of the idiomatic Sabar rhythms, the table is organized according to the categories of the corresponding spoken expressions (the Wolof correlates of idiomatic Sabar rhythms are complex expressions). The Sabar rhythms in Table 3 were all contributed independently by at least four differ- 
ent griots from the same group. Wolof does not have a clear lexical class of adjectives (McLaughlin 2004), although many Wolof verbs have adjectival English correlates. For instance, the word weex in 4 is a stative verb that can be translated as 'to be white'. For convenience, rhythms for 'adjectival verbs' are set apart as a special lexical category, and they are glossed as English adjectives. In Table 3, the rhythms for nonadjectival verbs were not contributed directly as Sabar parallels of separate spoken words, but were inferred from sentential Sabar rhythms (§5.2). The variation of Sabar rhythms for these verbs in the sentences checked was great, and the rhythms given in Table 3 are some of those from the responses discussed in $\$ 5.2$ in relation to negation. Another cautionary remark concerns the SW words axayo 'hungry', miki '2sG', and maga '3sG.M'. These words are the only ones in Table 3 that are not in Wolof. However, as pointed out by a referee, they are also not standard Serer-Sine. In a few cases like this, where the words were not familiar to the Wolof research assistants, I could not verify if the words belong to some recognized variety of Wolof or Serer-Sine. It is quite possible that these expressions are special family registers. Note that a semi-official secret variety of Wolof (Kàll) is well known in Senegal (Ka 1989, Peng 2013:235).

\begin{tabular}{|c|c|c|c|}
\hline SPEECH & GROUP & MEANING & RHYTHM \\
\hline \multicolumn{4}{|c|}{ IDIOMATIC SABAR RHYTHMS (5B) } \\
\hline kaay wan më & SW & 'come show me' & ce rwan rwan tan gin \\
\hline jox më & SW & 'bring me' & $\tan \tan$ \\
\hline \multicolumn{4}{|l|}{ COMMON NOUNS } \\
\hline lekk & LW & 'food' & ce gin \\
\hline ndox & LW & 'water' & pax \\
\hline duus (bi) & LW & 'bathroom (DEF)' & gin gin \\
\hline café & RW & 'coffee' & ce gin \\
\hline \multicolumn{4}{|l|}{ VERBS $(§ 5.2)$} \\
\hline naan & SW & 'drink' & $\tan$ gin $\tan$ \\
\hline nelaw & SW & 'sleep' & $\tan$ tac tac \\
\hline lekk & SW & 'eat' & gin tan gin \\
\hline dox & SW & ‘walk’ & tac tac tac \\
\hline bëgga & SW & 'want.1sG' & gin tan \\
\hline \multicolumn{4}{|c|}{ ADJECTIVAL VERBS } \\
\hline axayo & SW & 'hungry' & rwan tan gin \\
\hline tàng & RW & ‘warm’ & $\tan$ gin \\
\hline ndaw & RW & 'small' & tac \\
\hline rafet & RW & 'pretty' & tac tac \\
\hline leer & LW & 'pale' & tan rwan rwan \\
\hline lëndëm & LW & ‘dark’ & $\tan \tan$ gin \\
\hline weex & SW & 'white' & gin tan rwan gin ña pax gin gin \\
\hline weex & RW & 'white' & rwe \\
\hline ñuul & SW & 'black' & ce gin \\
\hline ñuul & RW & 'black' & gin \\
\hline xonq & SW & 'red' & gin pax ce \\
\hline xonq & RW & 'red' & pax \\
\hline \multicolumn{4}{|c|}{$R W$ and $S W$ griots also have rhythms for 'blue', 'green', and 'yellow'. } \\
\hline \multicolumn{4}{|c|}{ PERSONAL PRONOUNS } \\
\hline dama & SW & '1sG' & $\tan$ gin \\
\hline miki & SW & '2sG' & ce gin \\
\hline maga & SW & '3sG.M' & rwe gin/gin tan/gin gin \\
\hline \multicolumn{4}{|c|}{ DEMONSTRATIVE PRONOUNS } \\
\hline lii & SW & 'this' & gin \\
\hline lë & SW & 'that' & $\tan \tan / g i n \tan$ \\
\hline lëlé & SW & 'that-one-over-there' & ce ce/gin tan tan \\
\hline
\end{tabular}

TABLE 3. Examples of Sabar lexemes. 
Two simple conclusions can immediately be inferred from the examples in Table 3. First, Sabar rhythms do not acoustically mimic speech phonetics or syllable structure. Second, prosodic parallels between Sabar and speech are common but not at all obligatory. For instance, in axayo-rwan tan gin 'hungry' (SW) and weex-rwe 'white' (RW), the numbers of syllables in the spoken expressions and drum strokes in the rhythms are equal. But this is not the case with weex-gin tan rwan gin ña pax gin gin 'white' (SW) and many other examples. The lack of clear acoustic parallelism is vividly illustrated by the rhythms played in DW for the imperatives gaawal 'hurry up' and ñëwal 'at leisure' (lit. 'come'). Both rhythms involve the same pattern of sabar strokes ( $\tan \tan \tan \tan \tan \tan$ gin tan gin tan gin tan), but onomatopoeically, the latter is played at a much slower tempo. (See example 4 in the online supplementary materials for video.) No parallel onomatopoeia is observed in spoken Wolof.

Another fact worth noting is that Sabar vocabularies reflect a very small part of the spoken vocabularies. Consider, for instance, the Sabar correlates of color terms. RW griots had at least six color terms in their Sabar dialect, for ñul 'black', weex 'white', xonq 'red', bulo 'blue', veer/vert 'green', and soon 'yellow'. SW griots also have parallels for these color terms in their Sabar variety, using different rhythms from the RW group. LW griots, by contrast, were not able to play Sabar correlates of these color terms, despite their use of the same terms in spoken (Lebu) Wolof. LW griots did contribute correlates for the Wolof adjectival verbs leer 'pale' and lëndëm 'dark'. Hence, the color-term paradigm of LW Sabar does not match their spoken Wolof. Such lexical variation between Sabar varieties may be expected from the crosslinguistic typology of color terms in Berlin \& Kay 1969 (see also Hale 1975). A natural hypothesis is that LW Sabar preserves an old color-term paradigm of Lebu Wolof. This hypothesis gains support from the common claim that the Lebu Wolof people, historically a fishermen people, are the original inhabitants of the Dakar area. It is possible that their Sabar variety has undergone less change than spoken Lebu Wolof. As further support for this hypothesis, note the French loanwords used in modern Wolof for some color terms (e.g. for blue, green, yellow, and rose).

5. Sabar morphosyntax. The focus in this article is on the ways in which complex Sabar rhythms are formed. This section shows that in addition to concatenation parallel to parataxis in spoken language, as in 4 above, Sabar rhythms also exhibit morphosyntactic procedures involving reduplication, displacement, or temporal rearrangements of drum beats, in contrast to adjacency in spoken expressions. Such nonconcatenative effects were characterized in rhythms corresponding to plurals, definites, and negation phrases in spoken Wolof. These effects are evidence of a productive grammar of Sabar rhythms that is partially autonomous with respect to the grammar of spoken language. Further evidence suggests restrictions on the productivity of Sabar grammar that follow from rhythmic restrictions on sabar music.

Complex Sabar rhythms can be described as the output of systematic operations on simpler Sabar rhythms. Some of these Sabar processes correspond to morphological processes in Wolof. Other Sabar formation processes correspond to syntactic formation of spoken sentences containing adjuncts, complements, and negation. To avoid prejudice on the processes involved in Sabar rhythm formation, it is not assumed that Sabar itself should be analyzed as containing word-like elements. ${ }^{11}$ For neutrality on

\footnotetext{
${ }^{11}$ The theoretical decision is complicated by the fact that experimenting with Sabar rhythms is easier when they correspond to multiword Wolof expressions. For similar questions on 'words' in sign language morphology, see, for example, Sandler \& Lillo-Martin 2000:542-48.
} 
this question, all processes that derive complex Sabar rhythms are referred to as SABAR MORPHOSYNTAX.

When comparing complex Sabar rhythms to their spoken parallels, I distinguish between CONCATENATIVE and NONCONCATENATIVE morphosyntactic correlations. In many cases of alignment between speech and Sabar, spoken expressions appear linearly adjacent to each other, and accordingly the parallel Sabar rhythms are concatenated. For instance, in example 4 we saw a rhythm for a Lebu Wolof sentence of the form 'goinside-house' concatenated with a rhythm for the word 'dark/pale'. This correlates with the linear adjacency between the two parts of the spoken sentence. When the speechdrum correlation respects linear order in this way, it is justified to assume that the complex Sabar rhythm is formed by the same rule that forms the parallel spoken expression, with a different modality of phonological realization. However, there are also complex Sabar rhythms that demonstrate operations like reduplication or transposition, diverging from linear parataxis in the parallel expressions. Analyzing complex rhythms in such nonconcatenative correlations requires morphosyntactic operations that are not simply parasitic on the grammar of spoken language. This section illustrates some concatenative and nonconcatenative correlations between Sabar and spoken language and discusses their implications for Sabar morphosyntax.

5.1. CONCATENATIVE CORRELATIONS. Formally, suppose that EXP, $\operatorname{EXP}_{1}$, and $\mathrm{EXP}_{2}$ are spoken expressions, with Sabar parallels $S(\mathrm{EXP}), S\left(\mathrm{EXP}_{1}\right)$, and $S\left(\mathrm{EXP}_{2}\right)$, respectively. In such cases, we say that the rhythm $S$ (EXP) shows a concatenative correlation with the spoken expression EXP if the following holds.

(6) $\mathrm{EXP}=\operatorname{EXP}_{1} \cdot \operatorname{EXP}_{2}$ and $S(\mathrm{EXP})=S\left(\mathrm{EXP}_{1}\right) \cdot S\left(\mathrm{EXP}_{2}\right)$

In words: the spoken expression EXP is a parataxis of $\operatorname{EXP}_{1}$ and $\mathrm{EXP}_{2}$; accordingly, the Sabar rhythm parallel to EXP is a concatenation of the Sabar rhythms for $\operatorname{EXP}_{1}$ and $\operatorname{EXP}_{2}$.

Consider, for instance, the following Wolof sentences and their Sabar correlates in the SW group.

(7) Wolof (SW)

$\begin{array}{lll}\text { jox më mburu } & \text { (bu rëy) } & \text { (bu neex) } \\ \text { bring me bread } & \text { (REL big) } & \text { (REL tasty) } \\ \text { tan tan gin gin }{ }^{12} & \text { (gin gin) } & \text { (gin tac) }\end{array}$

'Bring me some (big) (tasty) bread.'

Each of the Sabar rhythms for the spoken expressions jox më mburu bu rëy, jox më mburu bu neex, and jox më mburu bu rëy bu neex is formed by concatenating the rhythm for jox më mburu with the rhythm for the relevant adjunct(s). Based on such tests we conclude that Sabar rhythms corresponding to adjunction of relatives show a concatenative correlation with their spoken parallels.

The same kind of correlation can be demonstrated by another simple test, that of adjunct transposition. Consider the following examples. ${ }^{13}$

\footnotetext{
${ }^{12}$ For the analysis of this complex Sabar rhythm see 10 below. An alternative Sabar rhythm for the expression jox më mburu is tan tan gin tan.

${ }^{13}$ The pronoun dama ' $\mathrm{I}$ ' in 8 is probably expressed here as rwan tan gin rather than tan gin, which was more commonly its Sabar rendition when requested in isolation (see Table 3). Similar variations with pronouns were common with the SW griots, as witnessed in many of their examples below.
} 
(8) Wolof (SW)
a. dama dem ci xale
I go to child
$\begin{array}{ll}\text { bu jeex } & \text { bu weex } \\ \text { REL thin } & \text { REL white }\end{array}$
rwan tan gin rwan tan tan tan gin
pax
gin tan rwan $\operatorname{gin}^{14}$
'I go to the thin, white child.'
b. dama dem ci xale
I go to child
rwan tan gin rwan tan tan tan gin
'I go to the white, thin child.'

$\begin{array}{ll}\text { bu weex } & \text { bu jeex } \\ \text { REL white } & \text { REL thin } \\ \text { gin tan rwan gin } & \text { pax }\end{array}$

(9) Wolof (Thiès)
a. yow jënd-ati-nga
thiakry
bu saf
REL sweet
te neex
you buy-again-2
Thiakry
gin tac
and tasty
rwan tan tan gin tan
pax ce ce gin
gin gin

gin tac

'You have again made sweet and tasty Thiakry (couscous and yogurt dessert).'
b. yow jënd-ati-nga thiakry bu neex te saf
you buy-again-2 Thiakry REL tasty and sweet
rwan tan tan gin tan paxce ce gin gin gin gin tac

'You have again made tasty and sweet Thiakry.'

In both 8 and 9 the Sabar rhythms involve simple transposition of the subrhythms corresponding to the transposed adjuncts (weex/jeex and saf/neex). ${ }^{15}$

The free addition and transposition of adjuncts makes it easy to demonstrate their concatenative correlations with Sabar. Another simple test for such correlations, which can also be illustrated with complements, involves substitution, as in the following example (SW griots).

(10) jox më mburu/ndox/kaas

bring me bread/water/glass

tan tan gin gin/pax/ce

'Bring me bread/water/a glass.'

The differences between the three rhythms tan tan gin gin, $\tan \tan$ pax, and $\tan \tan c e$ in 10 correspond to the different common-noun complements. The idiomatic rhythm for the shared constituent jox më (Table 3) remains constant as tan tan. The conclusion is that complementation processes as in 10 also show a concatenative correlation between Sabar rhythms and their spoken parallels.

5.2. NonCOnCATENATIVE CORRElations. Concatenative correlations are consistent with the a priori plausible hypothesis that complex Sabar rhythms are formed by the same morphosyntactic rules as their spoken parallels. This section, however, shows nonconcatenative correlations between Sabar and spoken expressions involving pluralization, negation, and definiteness. The Sabar rhythms that show such nonconcatenative correlations cannot be fully analyzed by the grammar rules underlying the parallel Wolof constructions.

\footnotetext{
14 This is a shortened version of the rhythm for weex played in isolation, given in Table 3.

${ }^{15}$ In 9 no difference was observed between the Sabar renditions of the relative marker $b u$ and the conjunction $t e$, which apparently are not represented in the rhythms of either sentence.
} 
Complex rhythms corresponding to plural nominal expressions often have an additional gin stroke at the end of the rhythm for the singular nominal. ${ }^{16}$ Consider the following examples from SW.

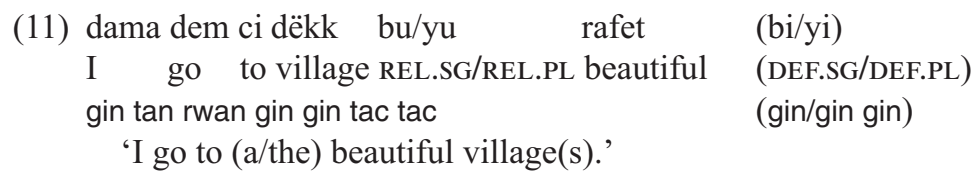

One difference between the indefinite Wolof sentences in 11 and their definite variants is expressed by the definite morpheme $b i$ (singular) or $y i$ (plural). ${ }^{17}$ The Sabar correlates of these singular/plural morphemes are one/two gin strokes, respectively. This is a common pluralization strategy in the SW and RW Sabar varieties. It has two straightforward analyses, as sketched below.

(i) The Wolof morphemes $b i$ and $y i$ are represented in Sabar by suffixing gin and gin gin, respectively.

(ii) Sabar expresses plural number by reduplicating the last stroke in the singular rhythm.

Analysis (i) assumes a suffixation process for Sabar pluralization, analogous to Wolof pluralization processes. ${ }^{18}$ Analysis (ii) assumes a reduplication effect, in contrast to Wolof. Crosslinguistically, both affixation of a constant morpheme and reduplication are attested as pluralization processes (Broselow \& McCarthy 1984, Frampton 2009, among others). In 11 it is hard to distinguish between the two analyses because the singular rhythm ends with a gin. A priori, for 11 we might prefer analysis (i) because of its simpler, concatenative, correlation with Wolof. Other examples, however, support the nonconcatenative correlation assumed in analysis (ii).

First, some Sabar plural forms of color terms in SW show reduplication, as well as other effects that are not in concatenative correlation with Wolof. For instance, the rhythms played for vertu bi/vert yi 'green DEF.SG/DEF.PL' are rwe and rwe rwe, respectively. These kinds of examples from SW griots may be viewed as lexical irregularity. With RW griots, however, whose spoken variety and Sabar practices are quite different from the SW griots, more substantial evidence was found for analysis (ii). Consider the following paradigm among RW griots. ${ }^{19}$

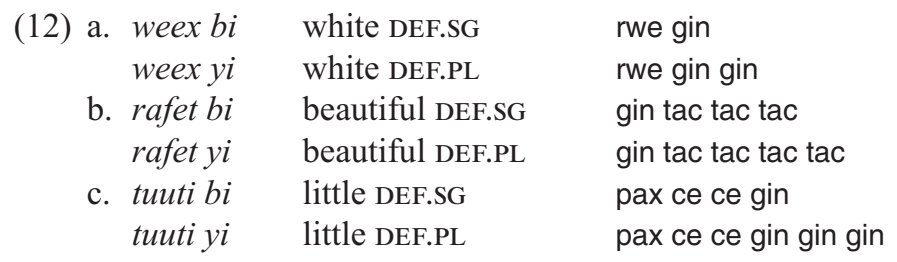

\footnotetext{
${ }^{16}$ As mentioned above, the gin stroke is often used in stylistic variations. In general, SW griots were consistent in their pluralization strategies, and added an additional gin to the plural rhythm even when the singular rhythm ended with more gins than usual (possibly for stylistic reasons).

${ }^{17}$ Number is also realized on the relative morpheme $b u / y u$. This difference is apparently not represented in Sabar.

18 Affixal morphological processes as in this Wolof example are often referred to as 'concatenative' (Carstairs-McCarthy 1992:82), which should be distinguished from the current use of the term 'concatenative correlations'.

${ }^{19}$ The adjectival verb rafet bi 'beautiful DEF.SG' in the tests reported in 12 was played as gin tac tac tac, unlike most of the sessions on which Table 3 is based, where bare rafet was played tac tac. The reasons for this variation are unclear. In $12 \mathrm{c}$ there are two added gin bass strokes in the plural rhythm as compared to the singular. As mentioned above, this kind of repetition with gin is quite likely for stylistic reasons.
} 

d. tuuti bi
little DEF.SG
gin ce ce ce
tuuti yi
little DEF.PL
e. tuuti bi
little DEF.SG
gin ce ce ce ce
*pax ce ce ce

In $12 \mathrm{a}$, where the singular rhythm ends with a gin, the same pattern is observed as in 11: an additional gin is suffixed in the Wolof plural expression. This is in line with both analyses (i) and (ii). By contrast, the singular Sabar rhythm in $12 \mathrm{~b}$ ends with a tac stroke, and the plural rhythm reduplicates it. This is expected by analysis (ii), but not by analysis (i). Further, for the singular expression tuuti bi 'little DEF.SG', two Sabar variations were accepted: $12 \mathrm{c}$ and $12 \mathrm{~d}$. As expected by the reduplication analysis in (ii), the plural versions of these rhythms repeat the last stroke, gin and ce, respectively. The affixal analysis in (i) does not predict this pattern. This is evidence that the productive rule for plurals in the RW Sabar variety involves reduplication. This reduplication cannot be described by assuming a constant singular/plural morpheme as in Wolof. Thus, the Sabar-Wolof correlation in the case of the RW plurals above is nonconcatenative, and this morphosyntactic behavior of Sabar cannot be described as parasitic on the grammar of spoken language.

The examples in 12 are also instructive in another respect. RW griots explained that the gin stroke in all of the singular rhythms $12 \mathrm{a}-\mathrm{d}$ is obligatory, and corresponds to the singular definite morpheme $b i$. As shown in $12 \mathrm{e}$, the griots rejected pax ce ce ce for tuuti bi, explaining that an obligatory gin is missing. In $12 \mathrm{a}$ and $12 \mathrm{c}$, the gin stroke is at the end of the rhythmic unit, whereas in $12 \mathrm{~b}$ and $12 \mathrm{~d}$ it appears at the beginning. This is further evidence for a nonconcatenative morphosyntactic correlation: the pronunciation of definiteness as the Sabar gin stroke is underdetermined by the obligatory position of $b i$ following the adjectival verb.

This behavior of RW Sabar rhythms for singular definites, together with analysis (ii) of pluralization, leads us to hypothesize the following correlation between RW Sabar and RW Wolof.

(13) Nonconcatenative Plurality and Definiteness Rule: The RW Sabar rhythms corresponding to singular definites (STEM. $b i$ ) and plural definites (STEM $\cdot y i)$ in Wolof are:

$S($ STEM $\cdot b i)=S($ STEM $) \cdot$ gin or gin $S S($ STEM $)$

$S(\operatorname{STEM} \cdot y i)=S(\operatorname{STEM} \cdot b i)$ with the last stroke reduplicated

This proposal accounts for the nonconcatenative correlations observed with RW griots.

A different nonconcatenative process with plurality is observed among the LW griots with the Lebu Wolof expressions ma doom (my.SG child) 'my child' and mai doom (my.PL child) 'my children'. These two expressions have different parallels in LW Sabar. Both rhythms have a ngax stroke followed by two gin strokes, and the difference between them is pronounced by different temporal arrangements of these strokes, illustrated in Figure 1. This is a nonconcatenative effect, because if the two gin strokes are assumed to be parallel to the possessive ma/mai, with a pause between them reflecting number, then the prenominal position of the Wolof possessive is not preserved in Sabar. If, by contrast, the difference in the pauses between the two gins is supposed to reflect a number agreement pattern on a Sabar noun phrase, then Sabar plural morphology differs from Wolof, which marks it on the possessive word. This nonconcatenative effect is likely to be productive in Sabar grammar, since LW griots could also play different rhythms for the expressions ma ñari/ñetti/ñenti doom 'my two/three/four children'.

Another case of nonconcatenative processes, where productivity is more easily attested, comes from the use of negation among the SW griots. Consider the examples in 


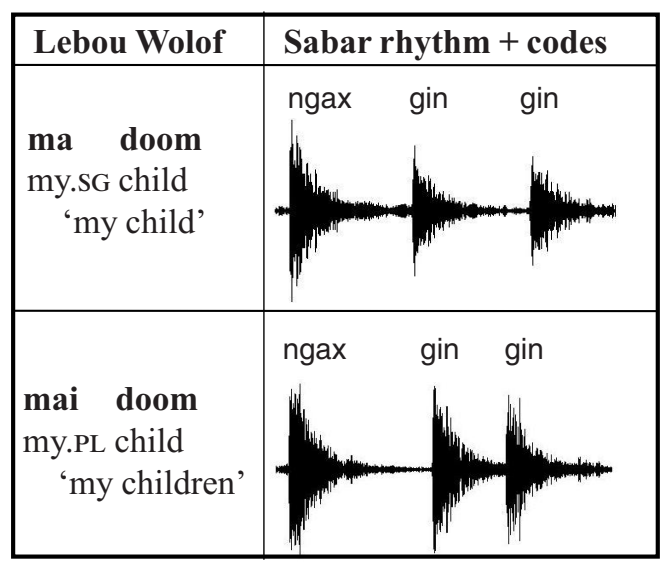

FIGURE 1. Lebu Wolof expresses the number of the spoken noun phrase ('my child/ren') on the possessive pronoun $\mathrm{ma} / \mathrm{ma}-\mathrm{i}$ ' $\mathrm{my} . \mathrm{SG} / \mathrm{my}-\mathrm{PL}$ '. By contrast, singularity/plurality of the parallel LW Sabar rhythm is expressed by the different temporal arrangement of the rhythms, but with no change in the drum strokes themselves: in the plural rhythm, the pause between the two gin strokes is shorter than in the singular rhythm.

14 of affirmative and negative modal sentences with the meaning 'I (do not) want to Verb'. For convenience, the Sabar rhythms corresponding to these sentences are also referred to as 'affirmative' and 'negative'.

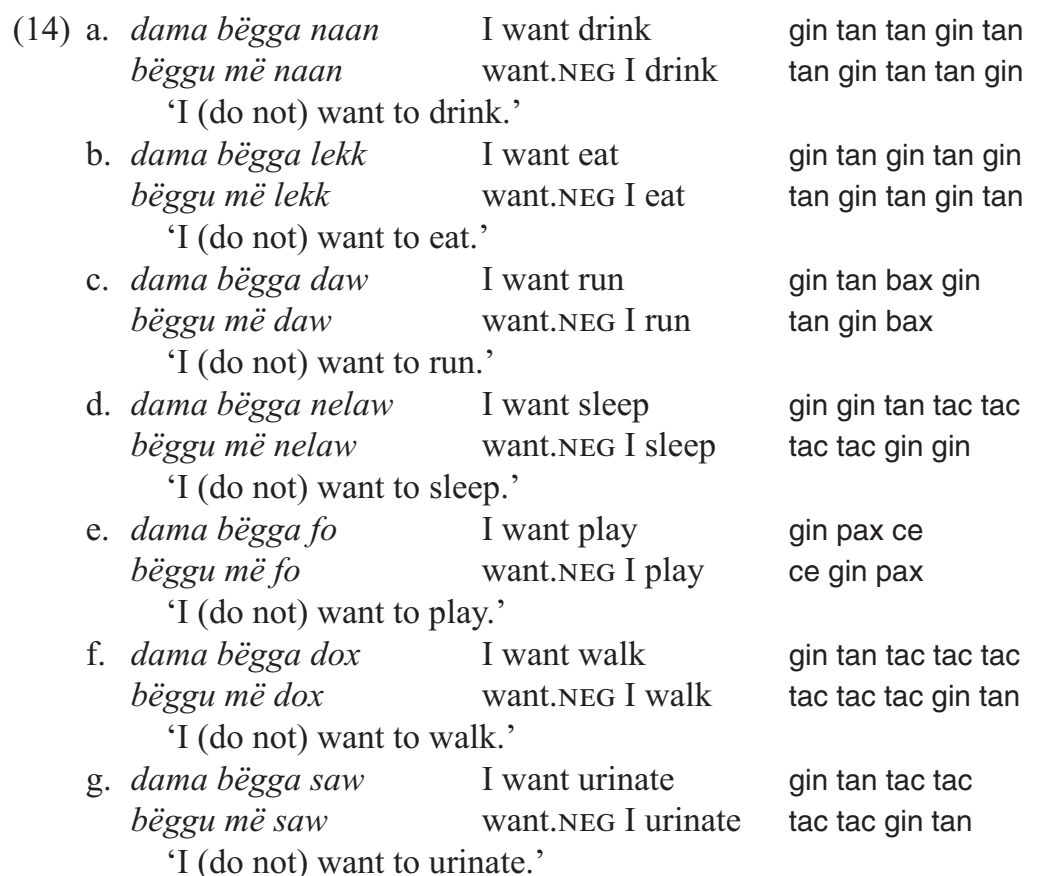

In all of the Wolof sentences in 14, the verb complement is at the end of both the affirmative sentence and the negative sentence. ${ }^{20}$ By contrast, its position is different in

\footnotetext{
${ }^{20}$ Negation in 14 is expressed in Wolof by changing the inflection of the verb (bëgga in the affirmative becomes bëggu) and replacing the first-person pronoun dama with a pronominal clitic më following the verb. For the syntax of negation in Wolof see Robert 1990, Buell et al. 2008.
} 
Sabar rhythms corresponding to the negative sentences. To highlight this fact, in Table 4 the rhythms in 14 are analyzed using the following notation.

- (X): part X of the rhythm, apparently used optionally for stylistic or other reasons

- $[X]$ : part X of the rhythm, apparently corresponding to the modal meaning 'I want'

- $\underline{X}$ : part X of the rhythm, apparently corresponding to the meaning of the complement verb (e.g. 'drink')

At the beginning of all of the affirmative rhythms in 14 except $14 \mathrm{e}$ appears the stroke tan with one or two preceding gins. As mentioned above, the bass stroke gin is often used for stylistic reasons at the beginning or the end of a rhythm. The analysis in Table 4 assumes that the initial gin tan part of the rhythm corresponds to the meaning 'I want', referred to here as the 'modal' part of the rhythm. The gin stroke within this part is assumed to be optional. The other part of the rhythm corresponds to the embedded verb (e.g. 'drink') and is referred to as the 'verbal' part of the rhythm. With this assumption, all of the NEGATIVE rhythms in 14, except that in 14c, can be represented as involving an inversion of the modal rhythm and the verbal rhythm. In $14 \mathrm{~b}$ and $14 \mathrm{e}$ the pattern is more complex than mere inversion: in $14 \mathrm{~b}$ the stroke tan is repeated twice, and in $14 \mathrm{e}$ the modal part is inserted in the middle of the verbal part, and is missing the tan stroke. On top of this pattern, in the two cases where the verbal part is not a palindrome in the affirmative (14c and 14e), it appears inverted in the corresponding negative rhythm. This may mean that negation also internally inverts the strokes of the verbal rhythm, but this point requires further research.

\begin{tabular}{|c|c|c|}
\hline AFFIRMATIVE & NEGATIVE & COMMENTS \\
\hline a. $[$ (gin) tan] tan gin $\tan$ & $\underline{\tan }$ gin $\tan [\tan ($ gin) $]$ & \\
\hline b. [(gin) tan] gin tan gin & $([\tan ])$ gin tan gin $([\tan ])$ & $\begin{array}{l}\text { One tan in the negative rhythm is } \\
\text { optional or agrees with the other tan. }\end{array}$ \\
\hline c. [(gin) tan] bax gin & [tan] gin bax & \\
\hline d. [(gin) gin tan] tac tac & $\underline{\text { tac tac }}$ [gin gin] & In the negative rhythm tan is replaced by gin. \\
\hline e. [gin] pax ce & $\underline{\text { ce }}$ [gin] pax & The missing tan in [gin] is unaccounted for. \\
\hline f. [gin tan] tac tac tac & tac tac tac [gin tan] & \\
\hline g. [gin tan] tac tac & $\underline{\operatorname{tac} t a c}[\operatorname{gin} \tan ]$ & \\
\hline
\end{tabular}

In all of the examples in 14 , the stroke that opens the affirmative sentential rhythm is a gin. However, for some of the sentences in 14, several SW griots also contributed alternative affirmative rhythms without a gin at the beginning. In such cases most of the corresponding negative rhythms start with a gin and do not involve the inversion patterns we saw in 14, but some other rhythmic manipulations (about which no generalizations have been found at this stage). Consider for instance the rhythmic variations for the same Wolof sentences in $14 \mathrm{a}-\mathrm{c}, \mathrm{f}-\mathrm{g}$.

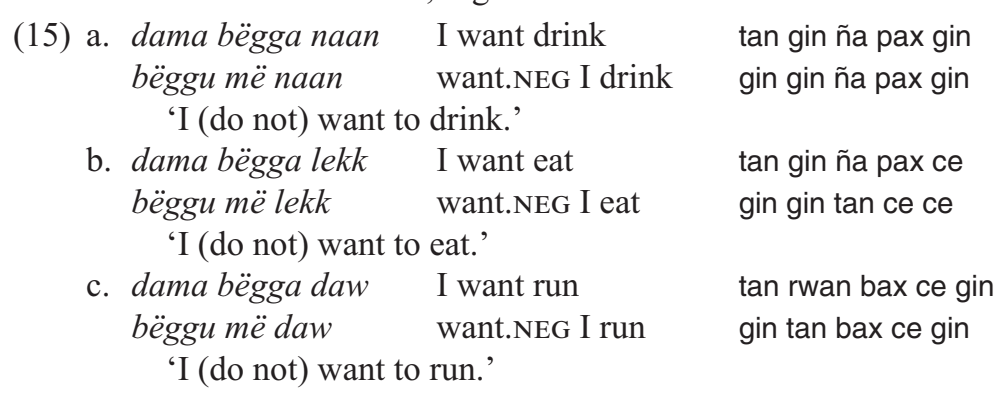



d. dama bëgga dox I want walk want.NEG I walk bëggu më dox walk.'
e. dama bëgga saw I want urinate bëggu mësaw want.NEG I urinate 'I (do not) want to urinate.'

The following rule approximates a generalization about Sabar negation among SW griots.

(16) Nonconcatenative Negation Rule (SW): Let $R=\left[R_{1}\right] \cdot \underline{R}_{2}$ be a rhythm for an affirmative modal sentence '[I want to] Verb'. If $R$ starts with a gin, the rhythm corresponding to the negative sentence 'I do not want to Verb' inverts the order of the modal rhythm and the verbal rhythm. If $R$ does not start with a gin, the negative rhythm prefixes a gin to some other manipulation of $R$ (not accounted for).

When tested with five different SW griots, the responses to the sentences in 14 and 15 varied quite a lot. But in thirty-three of the forty-six responses collected, the rule in 16 holds. In eleven of the forty-six responses, it was hard to find any clear formal relation between the affirmative rhythm and the negative rhythm, and in two responses the rhythm for the negative showed inversion patterns while the affirmative did not start with a gin.

A full account of negation in SW Sabar would require further research. Here, the motivation for analyzing Sabar negation is to test (non)concatenative relations between Sabar and Wolof. The affirmative cases allowed us to identify rhythm parts that correspond to the pronoun and modal verb, and parts that correspond to the complement verb. When these Sabar constituents were identified, they, or variations thereof, were also observed in the negative rhythms. In the sentences in 14, the alignment that emerges between the negative rhythm and the negative sentence is clearly nonconcatenative: the rhythm part corresponding to the verb appears at the beginning of the Sabar rhythm, unlike in the corresponding Wolof sentence. The data in 15 make the possibility of a general concatenative relation even less likely. Although more data are needed on negation in Sabar, the clear absence of concatenative correspondences between rhythm and speech is what is most relevant for the purposes of this article.

5.3. Discussion: Sabar grammar and Sabar productivity. In their linguistic interviews about the data in $\S \S 5.1$ and 5.2, most griots were able and willing to contribute Sabar parallels for spoken expressions that they were not likely to have heard before. Thus, it is natural to hypothesize that, similarly to grammars of spoken languages, Sabar grammar should model an ability to form an unlimited number of different meaningful forms on the basis of a finite lexicon. As supporting evidence for this hypothesis, consider the following example of verbal adjective adjunction.

(17) dama dem si xale bu xonk, bu weex, bu jeex, bu xiif

I go to child REL red REL white REL thin REL hungry

'I go to (the) red, white, thin, hungry child.'

The Wolof sentence in 17, with four adjectival verbs, together with its Sabar parallel, was spontaneously improvised by A. D., the leader of the SW griot group, in one of the interviews testing Sabar adjunction. From this and similar examples, it is plausible to conclude that Sabar grammar allows forming rhythms of unbounded length, similarly to grammars of spoken languages. 
Notwithstanding, griots' generative capacity in Sabar does not always so closely correspond with spoken language. Performance of rhythms in Sabar is restricted by one musical factor that is not dominant in ordinary use of spoken language: the need to match a constant beat. Griots often found it difficult to play rhythms parallel to very long sentences based on various grammatical patterns, even when shorter sentences containing the same lexical material, or other syntactic patterns of the same length, did not prove problematic. For instance, before spontaneously improvising sentence 17 with its four adjuncts and the Sabar parallel, A. D. had found it hard to play correlates to other sentences containing only three of the four adjuncts. Sabar musical practices offer a simple account of such performance effects, which from a formal linguistic perspective may seem puzzling. As A. D. explained, the rhythmic pattern $\int \% d d$ is at the basis of Sabar rhythms (see also Tang 2007:98). Making a Sabar rhythm match this musical pattern takes some artistic skill and inspiration. As Sabar rhythms get longer-ten seconds in the case of A. D.'s rendition of 17-finding their musically acceptable arrangement becomes more challenging. Thus, while modifier iteration suggests that productivity is a core property of Sabar grammar, performance is restricted by musical constraints, especially meter, similarly to other forms of musical creativity and poetic invention. Nketia's remarks about the musical basis of Akan speech surrogacy equally hold of Sabar.

To see if Sabar allows other productive strategies beyond iteration as in 17, another pilot study tested productive patterns in Sabar that would require hierarchical embedding. Insecure judgments on cases of complement embedding (e.g. 'I go to the child who likes rice') did not show a clear pattern. These cases may be too hard to play, and it proved hard to come up with other cases of structural embedding that could be more easily played. However, Eric Reuland (p.c.) suggests that since embedding also has a semantic dimension, even transitive sentences like 'boy saw girl REL white' may be a test for embedding if the adjunct unambiguously pertains to one of the arguments. Further study of such semantic tests for embedding must be left for future research.

With these provisions about Sabar performance and embedding, I conclude that griots' grammatical competence allows them to generate an unlimited number of Sabar rhythms. Another central question is whether the grammar that derives Sabar rhythms is the same as the grammar of a griot's spoken language. We have seen various tests that illustrate concatenation in Sabar rhythms in correlation with surface parataxis in spoken expressions. These examples are consistent with the a priori plausible hypothesis that Sabar rhythms are simply derived by concatenating rhythmic 'translations' of spoken lexical items. However, we have also seen that Sabar rhythms for plurals, definites, and negated sentences manifest nonconcatenative correlations with the corresponding spoken expressions. Such nonconcatenative correlations can be accounted for by one of the following alternative explanations.

(i) We may assume that on top of a concatenative use of the grammar of spoken language, griots also memorize a list of 'exceptional' Sabar rhythms, including those in $\$ 5.2$, which are not derived by any grammar at all.

(ii) Alternatively, we may postulate that our structural descriptions in 13 and 16 - of Sabar plurality, definiteness, and negation - manifest approximations of independent grammar rules of Sabar rhythms that diverge from the grammar of spoken language.

Hypothesis (i) would entail that all Sabar rhythms are derived from ordinary language, with a long list of idiomatic rhythms that would have to be memorized. There is no way to rule out such hypotheses completely: no empirical test can distinguish the strategy of 
adding a finite number of stipulations from a more principled theory of grammar. However, (i) is unlikely as an explanation of the facts that have been described above. To make (i) plausible, we would have to assume that for some reason the nonconcatenative effects we have seen are all exceptional in some way - that is, in some sense they are 'more idiomatic' than concatenative effects. No evidence was found to support such an assumption. Hypothesis (ii), which is adopted here, offers a simpler account of the facts. According to this hypothesis, all Sabar rhythms that are not frozen idiomatic expressions (class A in 5 above) are derived by the same productive Sabar grammar, which at least in some points diverges from the grammar of spoken Wolof.

Before drawing more general conclusions from this work, some of its limitations should be pointed out, as well as the immense gaps in our current knowledge and the room they leave for further research. First, this work did not attempt to give a linguistically comprehensive description of any of the four Sabar varieties that were studied. A preliminary condition for such an enterprise would be to find a suitable community of griots. Three parameters are crucial: the size of the community, the griots' proficiency in their local Sabar variety, and the linguistic richness of that variety. As mentioned in $\S 3$, the changes in modern Senegal make it hard to find communities that would pass all strict thresholds for an in-depth linguistic study. However, most of the griots who were asked about it believe that Sabar traditions are vibrant enough to make the project viable. Such research may also allow us to check another aspect of this work, which I had to leave aside: the analysis of naturally occurring uses of Sabar as in 1. At present it is unknown to what extent such contexts respect the grammatical richness of Sabar, and whether they may allow us to find more grammatical constructions in it. The linguistic documentation and analysis of naturally occurring Sabar utterances is a big project on its own. An even bigger project would analyze the current diversity in the Sabar heritage of Senegal and develop a comprehensive typology of existing Sabar traditions in various communities. More generally, and perhaps most urgently, linguists need to develop a comprehensive typology of drum languages in Africa, where many invaluable traditions are currently endangered.

6. ConClusions. This article has shown evidence that drumming traditions of sabar griots exhibit grammatical phenomena, which are collectively referred to as Sabar. It is proposed that Sabar can best be viewed as a collection of language varieties, with lexicons and productive grammars of their own. Despite their language-like forms, however, the main communicative function of Sabar rhythms is to affect the hearers rather than to efficiently convey propositions. Thus, in terms of functionality, it is more natural to categorize Sabar as 'music' rather than 'language'. This apparent discrepancy between form and function raises a number of questions. If Sabar rhythms are mainly used for musical purposes and not for speech surrogacy, what then is the function, if any, of their grammatical properties? Why should a medium that is primarily used for nonpropositional communication have such a close contact with grammatical faculties?

One aspect of these questions concerns the philosophical and methodological debate between 'formalist' and 'functionalist' approaches to language (Searle 1972, Davidson 1984, Nichols 1984, Newmeyer 1998, Tirumalesh 1999). The functionalist approach proposes that many linguistic structures can be explained on the basis of their usage for communication. The formalist approach sees language structures as first of all reflecting combinatorial properties of the brain, which are not explained by their communicative value. As we have seen, the structures of Sabar are similar to those of spoken language, but Sabar is not used for propositional communication. This lends support to 
the formalist thesis, at least to the extent that nonconcatenative strategies are manifested in Sabar. Nonconcatenative correlations like the ones studied here cannot be derived by directly translating speech to rhythms. Hence they demonstrate grammatical processes that are independent of language use for propositional communication, but are still very similar to grammatical processes in spoken languages. Under the functionalist view of language, it is unclear why Sabar grammar should be similar to those of languages that support propositional communication. The formalist view fares better on this question, since to begin with it views communication as having little explanatory power with respect to the structural properties of language. Whether and how these ideas on the findings of this article may relate to ongoing debates on language evolution is a question for further research.

Another important question on Sabar use is whether its grammatical properties contribute to its artistic functions. What does the correlation between speech and rhythms contribute? This question also involves addressing more general questions about the relation between language and music or other forms of affective communication. Previous works have suggested various structural parallels between language and music (Lerdahl \& Jackendoff 1983, Patel 2008, Katz \& Pesetsky 2011). Under these analyses it is not surprising to find musical functions for structures that show considerable grammatical regularities. Arguably, analyzing the details of the language-music contact in Sabar and other drum languages enhances our understanding of the parallelisms between music and language. More generally, Sabar is only one of many secondary linguistic systems. Across cultures there is a remarkable variety of documented drum languages, sign languages in hearing communities (Umiker-Sebeok \& Sebeok 1978, Kendon 1988), and whistled speech phenomena (Busnel \& Classe 1976, Meyer 2008). These systems provide useful evidence for the study of language in relation to other faculties (music, gesture, dance), but so far there has been little theoretical research on this vast topic. The present work illustrates the value of this line of research. Hopefully, it will contribute to further studies of the relations between language and other mental faculties.

\section{APPENDIX: PRACTICAL ASPECTS OF THE RESEARCH}

PREPARATION AND WORK WITH RESEARCH ASSISTANTS. The research was assisted by two accomplished Wolof griots living in Europe. Prior to the first research trip to Senegal, the assistants had worked with the author as consultants in the Netherlands. As professional Senegalese musicians who were raised in native griot families, the experience of the assistants with the research work, their deep knowledge of sabar practices, and their working contacts with other griots and with the author were imperative for the research.

Organizational MATters. Most interviews took place in Dakar, either in a quiet room or on an open, private balcony. The griots that were interviewed had been selected by the group leader. Leaders were requested to select those griots that had most closely played with them or with older senior griots of the same family. All griots were paid according to standard payment to professional musicians in the Netherlands. Logistics often involved bringing griots together from various locations. Accordingly, meals were organized for the researchers and griots together, and travel expenses were reimbursed.

DocUmentATION AND COPYRIGHTS. Most of the sessions were recorded on video, audio, or both. Griots showed keen interest that their copyrights for the work would be respected and the footage would not be distributed. It was clarified to them that no audiovisual material would be distributed without their explicit consent. Contracts to the effect were signed when requested.

SOCIOLOGICAL FACTORS AFFECTING LINGUISTIC INTERVIEWS WITH GRIOTS. Most of the griots had very little formal education, and many of them were illiterate to various degrees. The kind of concentration required for linguistic tests was obviously trying on many of them (on first encounters, remarks to the effect that the task or the author was 'insane' were not unusual). Still, as the work progressed most griots showed increased patience with the questions and overall appreciation of the research aims. 
COURSE OF INTERvIEws. There were two types of interviews: (i) individual interviews, and (ii) interviews with two or more griots simultaneously, including the group leader. The individual interviews were for both the free-response tasks and the acceptability-judgment tasks ( $\$ 3)$, whereas the group interviews were mostly for the free-response tasks. Individual interviews were carried out when subtle evidence had to be corroborated (e.g. for the data in Fig. 1, or in 14-15). For most purposes, however, it proved better to let two or more griots sit together in an interview, as this more naturally corresponds to the circumstances in which sabar is played. The group setting was especially convenient for creativity with unfamiliar linguistic utterances. Most interviews had the following structure:

1. invitation to play together freely with the griot research assistants $(5 \mathrm{~min}$.)

2. introduction of author and research assistants

3. basic personal questions: age, birth place, dwelling places, family relation to leader, musical experience with family (most but not all griots had played with the leader since childhood)

4. linguistic interrogation (40-50 min. on average)

5. more group playing with research assistants $(5 \mathrm{~min}$.)

When possible, the author had previously prepared material for the linguistic tests based on prior interviews with the group leader. These materials were presented by the Wolof research assistants, who acted as translators and helped with the transcription of the rhythms. In many cases the author came up with new questions during the interview when clarifications were needed, or when new aspects of the data were discovered.

\section{REFERENCES}

Arom, Simна. 1991. African polyphony and polyrhythm: Musical structure and methodology. Cambridge: Cambridge University Press.

Arom, Simha. 2007. Language and music in fusion: The drum language of the Banda Linda (Central African Republic). Trans: Revista Transcultural de Música 11. Online: http:// www.sibetrans.com/trans/publicacion/4/trans-11-2007.

Berlin, Brent, and PAul KaY. 1969. Basic color terms: Their universality and evolution. Berkeley: University of California Press.

Broselow, Ellen, and John J. McCarthy. 1984. A theory of internal reduplication. The Linguistic Review 3.25-88.

Buell, Leston Chandler; Mariame Sy; and Harold Torrence. 2008. The order of affixes and mirror principle violations in Wolof. Paper presented at the Berkeley Workshop on Affix Ordering, October 2008.

Busnel, René Guy, and André Classe. 1976. Whistled languages. Berlin: Springer.

Carrington, John F. 1949. Talking drums of Africa. London: Harvey Kingsgate.

CARSTAIRs-McCarthy, AndRew. 1992. Current morphology. London: Routledge.

Cloarec-Heiss, France. 1999. From natural language to drum language: An economical encoding procedure in Banda-Linda (Central African Republic). Language diversity and cognitive representations, ed. by Catherine Fuchs and Stéphane Robert, 145-57. Amsterdam: John Benjamins.

DAVIDSON, DonALD. 1984. Communication and convention. Synthese 59.3-17.

Diagne, Pathé. 1971. Grammaire de Wolof moderne. Paris: Présence Africaine.

Frampton, John. 2009. Distributed reduplication. Cambridge, MA: MIT Press.

Gamble, David P. 1957. The Wolof of Senegambia: Together with notes on the Lebu and the Serer. London: International African Institute.

Gelfand, AleXANDer Lyon. 2000. Rhythms of power: Royal drumming in Aburi-Akuapem, Ghana. Urbana-Champaign: University of Illinois at Urbana-Champaign dissertation.

Hale, Kenneth L. 1975. Gaps in grammar and culture. Linguistics and anthropology: In honor of C. F. Voegelin, ed. by M. Dale Kinkade, Kenneth Hale, and Oswald Werner, 295-315. Lisse: Peter de Ridder.

Hale, Thomas A. 1998. Griots and griottes. Bloomington: Indiana University Press.

Irvine, Judith T. 2011. Societé et communication chez les Wolof à travers le temps et l'éspace. Communication wolof et société séneégalaise: Héritage et création, ed. by Anna M. Diagne, Sascha Kesseler, and Christian Meyer, 37-70. Paris: L'Harmattan.

Ka, Omar. 1989. Wolof syllable structure: Evidence from a secret code. Eastern States Conference on Linguistics (ESCOL '88) 5.261-74. 
KA, OMar. 1994. Wolof phonology and morphology. Lanham, MD: University Press of America.

Katz, Jonah, and David Pesetsky. 2011. The identity thesis for language and music. Cambridge, MA: MIT, Ms. Online: http://ling.auf.net/lingbuzz/000959.

Kendon, AdAm. 1988. Sign languages of Aboriginal Australia: Cultural, semiotic and communicative perspectives. Cambridge: Cambridge University Press.

Koelsch, Stefan; Elisabeth Kasper; Daniela Sammler; Katrin Schulze; Thomas Gunter; and Angela D. Friederici. 2004. Music, language and meaning: Brain signatures of semantic processing. Nature Neuroscience 7.302-7.

LERDAHL, FRED, and RAY JACKENDOFF. 1983. A generative theory of tonal music. Cambridge, MA: MIT Press.

McLaughlin, Fiona. 1992. Noun classification in Seereer-Siin. Austin: University of Texas at Austin dissertation.

McLaughlin, Fiona. 2001. Dakar Wolof and the configuration of an urban identity. Journal of African Cultural Studies 14.153-72.

McLaughlin, Fiona. 2004. Is there an adjective class in Wolof? Adjective classes: A crosslinguistic typology, ed. by R. M. W. Dixon and Alexandra Y. Aikhenvald, 242-62. Oxford: Oxford University Press.

McNeE, Lisa. 2000. Selfish gifts: Senegalese women's autobiographical discourses. Albany: State University of New York Press.

Meyer, Julien. 2008. Typology and acoustic strategies of whistled languages: Phonetic comparison and perceptual cues of whistled vowels. Journal of the International Phonetic Association 38.69-94.

Munro, Pamela, and Dieynaba Gaye. 1991. Ay Baati Wolof: A Wolof dictionary. (UCLA occasional papers in linguistics 9.) Los Angeles: University of California, Los Angeles. Online: http://www.linguistics.ucla.edu/publications/opl_19.pdf.

Newmeyer, Frederick J. 1998. Language form and language function. Cambridge, MA: MIT Press.

Nichols, Johanna. 1984. Functional theories of grammar. Annual Review of Anthropology $13.97-117$.

Nketia, Joseph Hanson Kwabena. 1963. Drumming in Akan communities of Ghana. Edinburgh: Thomas Nelson \& Sons.

Nketia, Joseph Hanson Kwabena. 1971. Surrogate languages of Africa. Current trends in linguistics, vol. 7: Linguistics in sub-Saharan Africa, ed. by Thomas A. Sebeok, 699732. The Hague: Mouton.

Patel, AniRuddh D. 2008. Music, language, and the brain. New York: Oxford University Press.

Peng, Long. 2013. Analyzing sound patterns: An introduction to phonology. Cambridge: Cambridge University Press.

Pinker, Steven, and Ray Jackendoff. 2005. The faculty of language: What's special about it? Cognition 95.201-36.

Robert, Stephane. 1990. Aperçu et reflexions sur la négation en Wolof. Linguistique Africaine 4.167-80.

Sandler, Wendy, and Diane Lillo-Martin. 2000. Natural sign languages. The handbook of linguistics, ed. by Mark Aronoff and Janie Rees-Miller, 533-62. Oxford: Blackwell.

Searle, John R. 1972. Chomsky's revolution in linguistics. The New York Review of Books, June 29.

Sebeok, Thomas A., and Donna Jean Umiker-Sebeok. 1976. Speech surrogates: Drum and whistle systems. The Hague: Mouton.

Senghor, LÉOPOLD SÉDAR. 1964. Liberté 1: Négritude et humanisme. Paris: Éd. de Seuil.

Tang, Patricia. 2007. Masters of the sabar: Wolof griot percussionists of Senegal. Philadelphia: Temple University Press.

TANG, PATRICIA. 2012. The rapper as a modern griot: Reclaiming ancient traditions. Hip hop Africa: New African music in a globalizing world, ed. by Eric Charry, 79-91. Bloomington: Indiana University Press.

TiRUMALESH, K. V. 1999. Grammar and communication: Essays on the form and function of language. New Delhi: Allied. 
Umiker-Sebeok, Donna Jean, and Thomas A. Sebeok. 1978. Aboriginal sign languages of the Americas and Australia. London: Plenum.

Villepastour, Amanda. 2010. Ancient text messages of the Yorùbá bàtá drum: Cracking the code. Surrey: Ashgate.

[y.winter@uu.nl]

[Received 13 June 2013;

accepted 15 October 2013] 